Research article

\title{
Survival $v s$. growth trade-off in early recruitment challenges global warming impacts on Mediterranean mountain trees
}

\author{
Raquel Benavides ${ }^{\mathrm{a}, *}$, Adrián Escudero ${ }^{\mathrm{b}}$, Lluís Coll ${ }^{\mathrm{c}}$, Pablo Ferrandis ${ }^{\mathrm{d}}$, Fabrice Gouriveau ${ }^{\mathrm{c}}$, \\ José A. Hódar ${ }^{\mathrm{e}}$, Romà Ogaya ${ }^{\mathrm{f}, \mathrm{i}}$, Sonia G. Rabasag ${ }^{\mathrm{g}}$, Elena Granda ${ }^{\mathrm{g}}$, Blanca P. Santamaría ${ }^{\mathrm{h}}$, \\ Jordi Martínez-Vilalta ${ }^{\mathrm{f}, \mathrm{j}}$, Regino Zamora ${ }^{\mathrm{e}}$, Josep M. Espelta ${ }^{\mathrm{f}}$, Josep Peñuelas ${ }^{\mathrm{f}, \mathrm{i}}$,
} Fernando Valladares ${ }^{g}$

a Albert-Ludwings-Universität Freiburg, Schänzlestraße 1, 79104 Freiburg, Germany

b Universidad Rey Juan Carlos, C/Tulipán s/n, 28933 Móstoles, Spain

c Centre Tecnològic Forestal de Catalunya, Crta. De Sant Llorenç de Morunys, km 2, 25280 Solsona, Spain

d Instituto Botánico de la Universidad de Castilla-La Mancha, Campus Universitario s/n, 02071 Albacete, Spain

e Universidad de Granada, Campus Fuentenueva s/n, 18071 Granada, Spain

${ }^{\mathrm{f}}$ CREAF, 08193 Cerdanyola del Vallès, Spain

${ }^{g}$ Museo Nacional de Ciencias Naturales-CSIC, C/Serrano 115 bis, 28006 Madrid, Spain

h Instituto de Ciencias Agrarias-CSIC, C/Serrano 115 bis, 28006 Madrid, Spain

${ }^{i}$ CSIC, Global Ecology Unit, CREAF-CSIC-UAB, 08193 Cerdanyola del Vallès, Spain

j Universitat Autònoma de Barcelona, 08193 Cerdanyola del Vallès, Spain

\section{A R T I C L E I N F O}

\section{Article history:}

Received 23 January 2015

Received in revised form 21 April 2015

Accepted 10 June 2015

Available online $\mathrm{xxx}$

\section{Keywords:}

Climate change

Climatic gradient

Demographic stabilising processes

Elevational shift

Forest regeneration

Mediterranean forests

Species distribution

\begin{abstract}
A B S T R A C T
Climate change is expected to alter the geographic distribution of many plant species worldwide. However, there is still no clear evidence showing a generalised direction and magnitude of these distribution shifts. Here, we have surveyed, in nine mountainous regions in Spain, an array of tree species along entire elevational ranges, as surrogates of their global climatic ranges, to test for elevational shifts towards cooler locations. We analysed the distribution recruitment patterns of five dominant tree species, recording the abundance and measuring the primary growth of juveniles in 306 plots. Three of the species have a temperate-boreal distribution with populations at their southern edge in the Mediterranean mountain ranges: Pinus sylvestris, Pinus uncinata and Fagus sylvatica; and the other two species have a Mediterranean distribution: Quercus ilex and Pinus nigra. Despite the contrasting phylogenies and biogeographies, we identified a similar pattern in recruitment abundance across species, with an asymmetric distribution of juveniles (more recruits in the middle-upper elevation of their range), but higher annual growths at lower elevations. This survival-growth trade-off at the early recruitment stage may potentially counterbalance at population level the negative effect of global warming on recruit survival at the lower edge of species ranges. These findings suggest a demographic stabilisation process at the early recruitment stage of these tree species, and highlight the importance of considering the different demographic stages across the whole climatic range to understand the effects that climate change may exert on species distributions and population dynamics.
\end{abstract}

(c) 2015 Geobotanisches Institut ETH, Stiftung Ruebel. Published by Elsevier GmbH. All rights reserved.
Abbreviations: Sampled transects' position along elevational gradients: U, upper; MU, mid-up; M, middle; ML, mid-low; L, lower transects; Se, seedlings emerged during the current growing season; S1, saplings from one to five years; S2, saplings over five years

\footnotetext{
* Corresponding author. Tel.: +49 76120326 23; fax: +49 7612032696.

E-mail addresses: rbenavidescalvo@gmail.com, raquel.benavides@biologie.uni-freiburg.de (R. Benavides).
}

\section{Introduction}

An increasing number of studies are showing latitudinal and elevational shifts of many species in response to climate change (Parmesan and Yohe, 2003; Rabasa et al., 2013). Although changes in traditional land uses contribute to some of these species distribution shifts (Peñuelas and Boada, 2003; Batllori and Gutiérrez, 2008; Ameztegui et al., 2010), most of the studies have suggested that global warming and the increased frequency of extreme climatic events are the main causes of gradual upward and poleward 
movements and consequent changes in the species composition of ecosystems (Wardle and Coleman, 1992; Peñuelas and Boada, 2003; Thuiller et al., 2005; Beckage et al., 2008; Bertrand et al., 2011b; Benavides et al., 2013; Matías and Jump, 2014). However, this evidence runs in parallel with other studies showing a lack of species distribution changes (Lenoir et al., 2009, 2010), species that have increased their cover and/or abundance with rising temperature or aridity (Wang et al., 2006; Gimeno et al., 2012) or even that have experienced a downslope range displacement (Lenoir et al., 2010; Crimmins et al., 2011; Rabasa et al., 2013).

Lloret et al. (2012) shed some light on these apparent contradictions suggesting that some stabilising demographic processes may mitigate or compensate the negative effects in plant communities induced by extreme climate events (Table 1 ). Within the mitigation category, local factors (both biotic, like facilitation, and abiotic, like physiography or site quality) may provide microrefugia and attenuate the direct negative effects of a changing climate on individuals (Pearson and Dawson, 2003; Araújo and Luoto, 2007; Dobrowski, 2011; McLaughlin and Zavaleta, 2012). Moreover, species-specific characteristics related to their adaptation or acclimation ability may also buffer the expected climatic impacts on populations (Aitken et al., 2008; Nicotra et al., 2010; Richter et al., 2012). Accordingly, recent studies have suggested that the direct impacts of global warming may be smaller than predicted, and have shown a high degree of homeostasis in different processes of some species in response to increasing temperatures (Gunderson et al., 2010; Baldi et al., 2012). Within a second category of compensatory processes, Lloret et al. (2012) included the beneficial effect that warmer temperatures may have over some life cycle stages and ecological processes. For instance, an increase in growth with temperature may compensate a lower seedling survival (Doak and Morris, 2010); or reduce current competitive or antagonistic interactions (McDowell et al., 2006; Carnicer et al., 2011), and increase mutualistic relationships (Le Conte and Navajas, 2008; GiménezBenavides et al., 2011).

The mismatch between both types of observational outcomes (shift $v s$. no-shift) may not only reflect the species-specific characteristics, but also differences in the spatial and temporal study scales. Undoubtedly, some species are more vulnerable to environmental changes and will respond earlier than others. Nevertheless, the studies showing shifts have been frequently conducted considering a single species or population, or have been focused on changes occurring at the edge of species ranges, being then unable to reveal the whole picture by neglecting the overall distribution of the species (but see these studies with waterbird species-Lehikoinen et al., 2013 and stream fish species-Comte and Grenouillet, 2013). Thus, it is a priority to conduct more comprehensive studies in which a set of species are simultaneously surveyed at several spatial scales, covering their whole distribution range (Lenoir and Svenning, 2015), and including different life stages (i.e. including the regeneration niche, see Grubb, 1977). This will shed light on the demographic mechanisms and tradeoffs involved in the shift $v s$. no-shift responses, and will help to identify global responses to current warming and design strategies to mitigate its impact over plant communities.

In this study, we contribute to this goal and we analyse the distribution of the recruitment (seedlings and saplings), in terms of abundance and primary growth, of four dominant tree species, surveying their entire elevational range in Mediterranean mountains, as a surrogate of the climatic range that each species experiences along their latitudinal distributions. Using elevation as a surrogate for climate range is a useful tool to study responses under different climatic scenarios within a single population and, therefore, minimising differences due to genetic variability, compared to surveys carried out in large areas, and therefore, including different populations (Ruíz-Benito et al., 2012; Vayreda et al., 2013; Carnicer et al., 2014). Three of the target species have a temperate-boreal distribution with populations at their global southernmost limit in the Iberian mountain ranges: Scots pine (Pinus sylvestris L.), mountain pine (Pinus uncinata Ramond ex DC.) and European beech (Fagus sylvatica $\mathrm{L}$.); and the other one has a Mediterranean distribution: Iberian black pine (Pinus nigra Arn. ssp. salzmannii (Dunal) Franco). Another Mediterranean dominant tree species was included in the target species pool of this study due to its great relevance in the Iberian Peninsula: holm oak (Quercus ilex L.). However, this species was not surveyed along its entire elevational range and its trailing edge was left out, because this species has no low elevational limit in the Mediterranean mountains. Our main aim is to test in the study populations whether there is an overall, pervasive elevational shift of the young cohorts towards cooler locations within the entire elevational range of the adult, which would be transferable to poleward shifts in response to the ongoing climate change, or if the altitudinal patterns are species-specific (Lenoir et al., 2009; Woodall et al., 2009). We expect that the recruits of the Mediterranean species, better adapted to summer drought, would be less affected by the ongoing climate change and be more abundant near their central part of the elevational range, where the density of conspecific adults and, therefore, seed rain are greater than at the edges of their range. By contrast, we expect that the species with populations at their trailing edge of their distribution, therefore marginal populations, would show shifts of their optimum juvenile abundance towards higher elevations (Matías and Jump, 2014). This outcome would show the different climatic conditions imposed by the global warming between the conditions when the current adult stand established, and the present situation. Hence, we hypothesise an idiosyncratic response of the different species with no general upward trend, and where a potential compensatory process enhancing the performance of the juveniles under warmer conditions may be relevant, especially for those species whose populations are at their southern limit.

\section{Material and methods}

\subsection{Study sites}

The study was conducted in nine mountain ranges across Spain during the early summer in 2010 and 2011 (Fig. 1). The entire

Table 1

Summary of the stabilising processes proposed by Lloret et al. (2012).

\begin{tabular}{|c|c|c|}
\hline Stabilising processes & Basis & Underlying predisposing factors/processes \\
\hline Mortality mitigation & $\begin{array}{l}\text { Existence of } \\
\text { microrefugia } \\
\text { Adaptation, acclimation ability }\end{array}$ & $\begin{array}{l}\text { Site quality } \\
\text { Facilitation } \\
\text { Tolerance } \\
\text { Plasticity } \\
\text { Phenotypic variability }\end{array}$ \\
\hline Mortality compensation & Enhanced future survival or recruitment ${ }^{\mathrm{a}}$ & $\begin{array}{l}\text { Beneficial effects of climate change } \\
\text { Release competition } \\
\text { Release antagonism } \\
\text { Increase mutualism }\end{array}$ \\
\hline
\end{tabular}

a By improvement of the conditions for recruits or adult reproductive performance. 


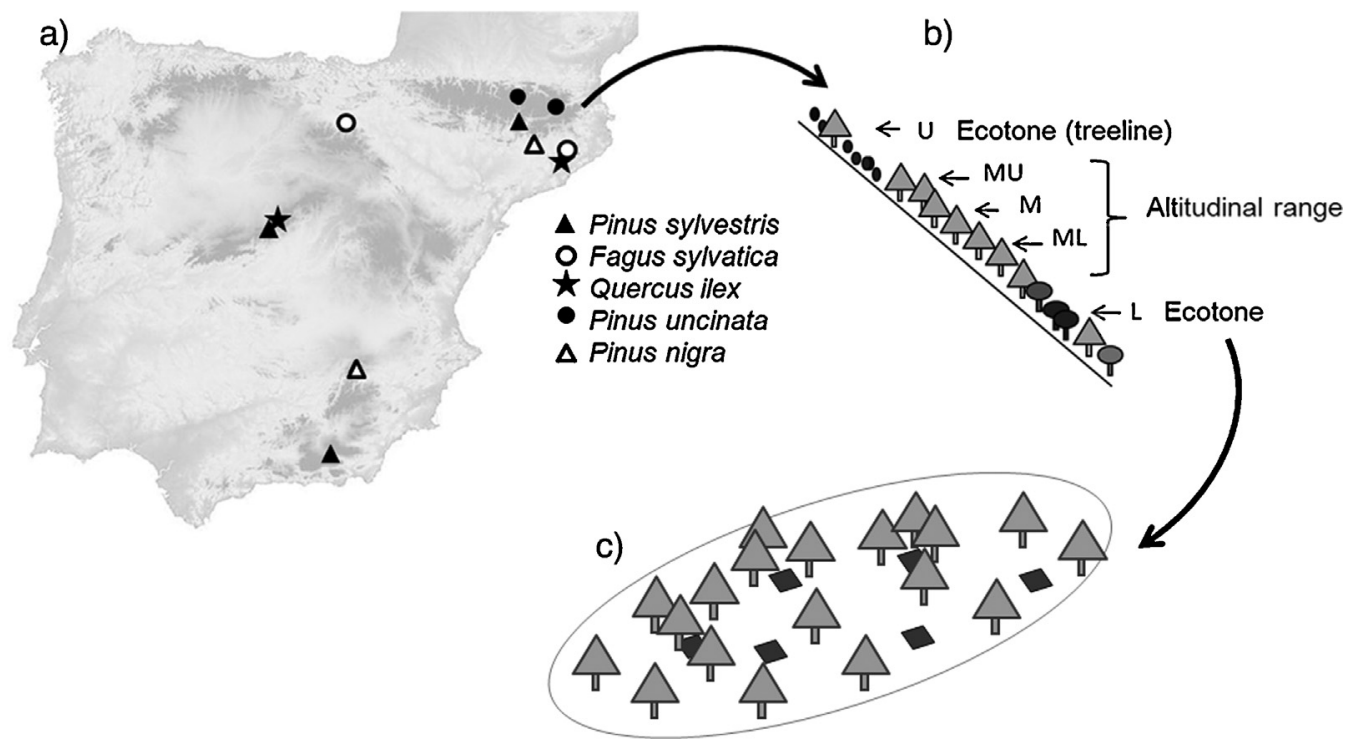

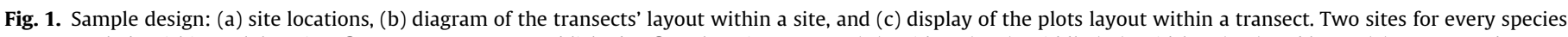

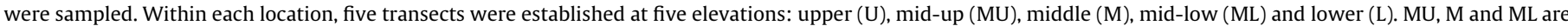

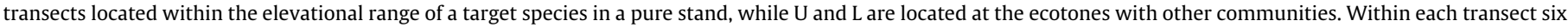
plots were established, three of them under fully canopy and the other three in gaps.

sampling required two years due to the short lapse of time between the emergence of most of the seedlings and the onset of the summer drought. For every species we sampled two natural pure stands located in different mountain ranges (three in the case of $P$. sylvestris), making a total of 11 study sites (see Supporting information, Table A.1). These stands showed neither visible signs of being planted, nor any evidence of management that could affect the current recruitment. Within each site, five transects were established at five elevational levels (Fig. 1). The upper (U) and the lower (L) transects were placed in the ecotones of each target species with the adjacent communities, and considered front and rear edges of their range, respectively. In the majority of the cases, $U$ transects were located at the treeline (i.e. transition from the uppermost closed forests to the treeless mountainous vegetation). The three intermediate levels: mid-low, middle and mid-up levels (henceforth ML, M, and MU, respectively) were evenly located within the elevational range of each species, with at least $100 \mathrm{~m}$ difference in elevation among them, being ML and MU located near the boundary with the ecotones (Fig. 1). In the case of $Q$. ilex, we only considered the three superior levels since this species has no low elevational limit in the Iberian Peninsula. Therefore, there was a total of 51 transects sampled ([3 species $\times 2$ sites $\times 5$ transects] $+[1$ species $\times 3$ sites $\times 5$ transects $]+[1$ species $\times 2$ sites $\times 3$ transects $]$ ).

\subsection{Recruitment sampling and environmental variable recording}

We established six plots $(4 \times 4 \mathrm{~m})$ within each transect, that is 306 plots in total ( 51 transects $\times 6$ plots), separated by at least $100 \mathrm{~m}$ (Fig. 1). Three plots per transect were haphazardly located under fully canopied stands, and the other three in small forest gaps to include contrasting conditions within each forest and elevation, avoiding ravines, boulders, cliffs or other geomorphologic elements which could bias our measurements ameliorating the effect of climate by local physiography (Dobrowski, 2011). In every plot we recorded the number of recruits by counting the seedlings recently emerged and saplings (up to $1.50 \mathrm{~m}$ tall). Seedlings and saplings of resprouting species ( $Q$. ilex and $F$. sylvatica) were correctly identified from vegetative offsprings following Espelta et al. (1995). We estimated the age of the recruits by counting the terminal bud scars (internodes) along the main stem and we sorted them into three different age classes (Espelta et al., 1995), assuming a different sensitivity to the environment (Collins and Carson, 2004): Se: seedlings emerged during the current growing season and without bud scars; S1: saplings from one to five years, that had thus experienced at least one summer drought and one winter; and S2: saplings over five years. The age of the individuals included in the last category was not fully dated due to the difficulty with distinguishing scars in the field as individuals grow and become woodier, but it was verified that they exceeded 5 years. We also measured the primary shoot growth in previous years (growths occurred in 2007, 2008 and 2009) and averaged them, as a proxy of their individual performance. We identified the current shoot (not considered for the study because the growing season was not finished when the sampling took place) and measured the length of the previous internodes along the main stem not damaged by herbivores. The existing literature demonstrated that shoot growth is a good indicator of environmental favourability (Willms et al., 1998), as well as the impact of drought conditions on plant growth (Mutke et al., 2003; Peñuelas et al., 2004; Thabeet et al., 2009).

Some biotic and abiotic environmental variables were assessed in each plot. All adult trees within a $10 \mathrm{~m}$ radius around the regeneration plot were mapped and their diameter at breast height - $d b h$ - was measured. Afterwards we calculated the basal area (both considering every adult tree and only the conspecific individuals) and tree density of adult trees of the target species in each plot. Finally, we translated the elevation and latitude of every plot (through the GPS coordinates) into climatic variables using the Climatic Digital Atlas of the Iberian Peninsula (Ninyerola et al., 2005) (see Supporting information Table A.1 and Fig. A.1).

\subsection{Data filtering and statistical analysis}

The abundance of the individuals of each species and age class along the elevation and temperature ranges was compared using the Kruskal-Wallis test. However, as the amount of seedlings (Se) varies greatly among years, we considered only the saplings (S1 and S2) for further analyses, i.e. survivors after the first summer 
drought, which is considered the main bottleneck for recruitment in Mediterranean areas (Jordano and Herrera, 1995; Castro et al., 2004; Giménez-Benavides et al., 2007; Linares and Tíscar, 2010).

We analysed the variation of the regeneration pattern along the elevational gradient. Hence, we compared our response variables along the five elevational levels (fixed variable) using Generalized Linear Models (GLM; McCullagh and Nelder, 1989) and Generalized Linear Mixed Models (GLMM; Breslow and Clayton, 1993). For the response variable abundance of saplings per species and at plot level (age class was neglected due to the low figures in some transects of these count data), we run GLMs and assumed a negative binomial distribution and a log link function. We selected this distribution after noticing the presence of over-dispersion (McCullagh and Nelder, 1989; Hoef and Boveng, 2007). In addition to elevational levels, two covariates describing the structure of the adults within a plot, therefore related to the seed rain, were considered to fit the models: tree density and mean $\mathrm{dbh}$ of conspecific adult individuals (Vayreda et al., 2013; Matías and Jump, 2014). Finally, the variable site was treated as a fixed factor due to the low number of levels (two/three for each species) to be considered a random effect (Crawley, 2002; Bolker et al., 2008).

The other response variable, the individual mean growth per species and age class along elevational levels was log-transformed and analysed assuming a normal distribution and an identity link function, using a mixed approach (GLMM). This time the sample size (data at individual level) allowed us to consider the age class, and a model for each age class was run separately. Light availability is one of the best predictors for saplings' growth (Gómez-Aparicio et al., 2008; Benavides et al., 2013). Therefore, this time the total basal area of the plot was included as a covariate, considered as an index of competition for light with adult trees (Urbieta et al., 2011). Concerning the random variables, we considered the hierarchical structure of the data, with likely different level of correlation among observations from the same site and plot (nested design).

To analyse the overall trend in the regeneration pattern across the different elevational levels, and make the data from different species comparable, we standardised the abundance and growth values per species, i.e. we subtracted from each value the species averaged abundance or growth, respectively, and divided it by the standard deviation. Then, we pooled the data and compared them along the elevation gradient (levels) using a GLMM. Similar to the analyses conducted per species, for abundance data we included the covariates density and mean $\mathrm{dbh}$. This time site was considered a random variable (with 11 levels), and we assumed a gamma distribution and a log link function (after adding two units to the standardised data to avoid negative values). For growth data we assumed a normal distribution, and we considered basal area as a covariate, and plot within site, as random factors.

We tested for significance of fixed effects comparing models with likelihood ratio tests, and we removed the covariates if they did not significantly improve the fits. The estimation of the parameters was done through Maximum Likelihood analyses for the GLMs, and for comparison between models with the same random structure (GLMMs), and through the Restricted Maximum Likelihood approach for assessing the parameters of the final selected GLMMs.

Finally, we implemented the Tukey's post-hoc test (Games and Howell, 1976) to examine significant differences in abundance and growth along the elevational levels for every single species and globally (i.e. for pooled standardised data). The GLMs and GLMMs were performed using packages MASS (Venables and Ripley, 2002), nlme (Pinheiro et al., 2014) and stats in R (R Core Team, 2013).

\section{Results}

\subsection{Distribution of juveniles along the elevation}

We recorded a total amount of 9310 juveniles in the 306 plots, sorted into 5283 juveniles of $P$. sylvestris, 547 of $Q$. ilex, 1143 of $P$. nigra, 740 of $P$. uncinata, and 1597 of $F$. sylvatica. The distribution of juveniles by age class (Fig. 2) along the elevation and temperature gradients showed a shift towards higher elevations within the elevation range of the adult individuals (therefore, towards cooler temperatures) of the saplings (particularly S1) of $Q$. ilex and pines, compared to the elevation at which most of the seedlings emerged. By contrast, F. sylvatica recruits occurred mainly in the lower areas (L), although there was no significant difference among the distributions of the different age classes.

\subsection{Abundance and growth of saplings along elevational levels}

Removing the seedlings (Se), the total amount of saplings found in the 306 plots were 3191 , sorted into 1367 saplings of $P$. sylvestris (surveyed within 90 plots), 543 of $Q$. ilex (within 36 plots), 564 of P. nigra (within 60 plots), 608 of $P$. uncinata (within 60 plots) and 109 of $F$. sylvatica (within 60 plots).

At tree species level (analyses per species), the GLM showed a similar trend for abundance data of saplings of all species along the elevational levels, with a significant effect but for $P$. nigra (Table 2; Fig. 3). The $U$ and L levels had the lowest saplings abundances. Focusing on the three intermediate elevational levels, all of them showed higher figures in MU than in the ML, with a significant difference for $P$. sylvestris and F. sylvatica. $P$. uncinata and $Q$. ilex had its maximum abundance of saplings at the MU level, showing an abrupt decrease between MU and U levels. Considering pooled data (global analysis), the estimates of the standardised mean abundance of saplings showed a significant difference among elevational levels as well (Table 2; Fig. 3), with the highest number of saplings appearing in the M level, and followed by MU. These numbers were significantly higher than those found at the ecotones (L and $U$ ), which accounted for the lowest figures.

Concerning the covariates included in the models for abundance estimation (Table 2), significant differences among sites hosting the same species appeared, but for $F$. sylvatica. Tree density did not appear as an important factor affecting saplings' abundance (except for $P$. nigra with a negative effect), while the mean $d b h$ of the adults affected positively the abundance of species with resprouting ability, i.e. F. sylvatica and Q. ilex.

Analyses run with mean annual growth data showed a clear decrease in annual growth for younger saplings (S1: from 1 to 5 years) with elevation, particularly when comparing $L$ and ML levels with higher ones, both considering data per species and pooled standardised data. For older juveniles (S2: over 5 years), there was a global slight increase upslope (Table 3; Fig. 4), but there were large differences in the trends of the different species. In addition, a generalised negative effect of the basal area appeared affecting annual growth (Table 3), although not significant for every species, and mainly affecting the old saplings (older than 5 years).

\section{Discussion}

Opposite to our hypothesis, and despite the contrasted phylogeny and biogeography of the study species, we identified common patterns in recruitment abundance and growth along climatic gradients for these species. This result is especially relevant when it is considered that recruitment is very dependent on local processes and hence, highly site-dependent (Gómez-Aparicio, 2008; Matías et al., 2011; Ameztegui and Coll, 2013; Benavides 

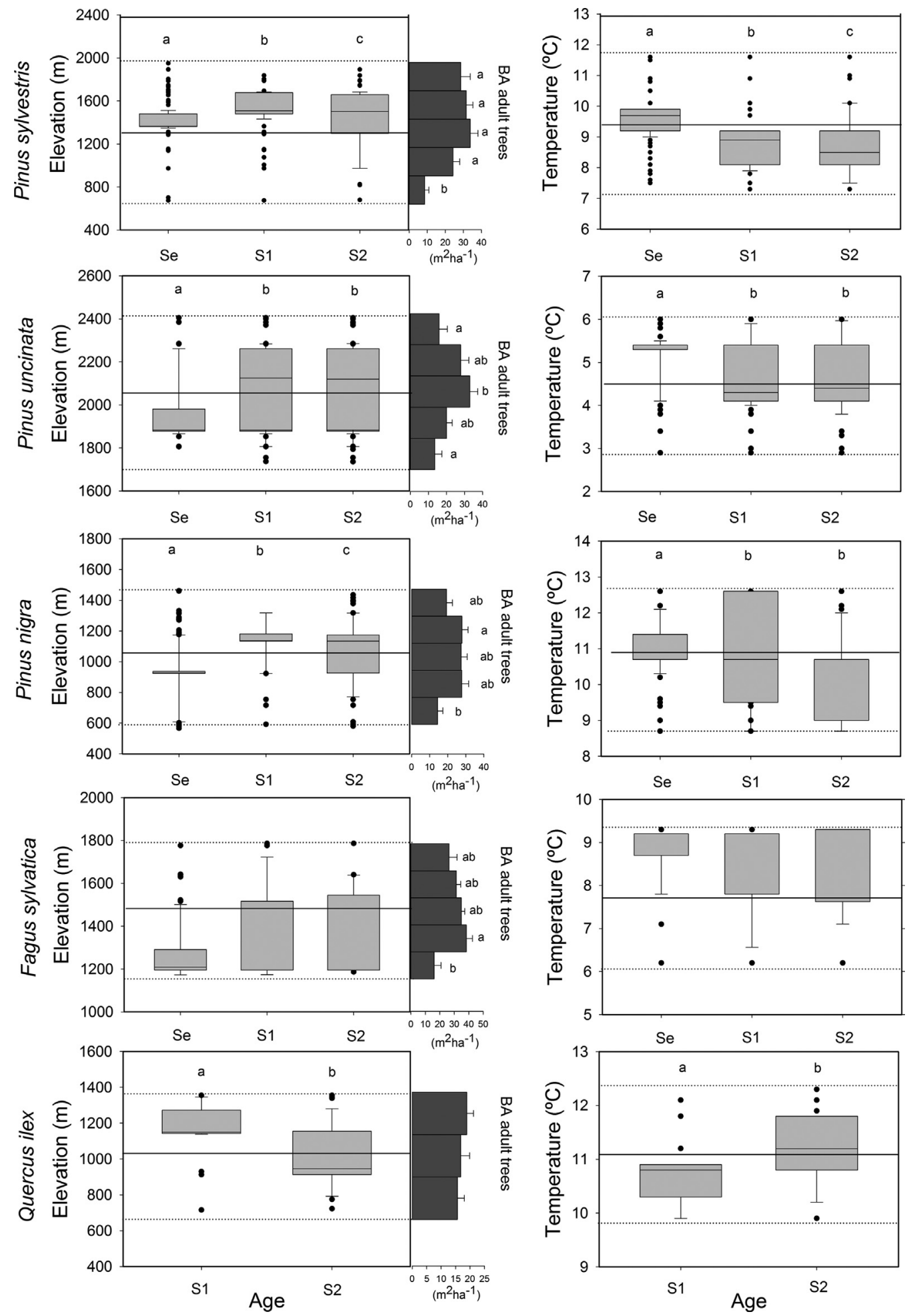

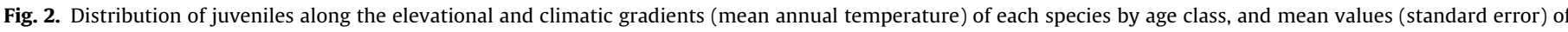

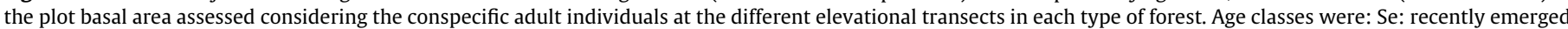

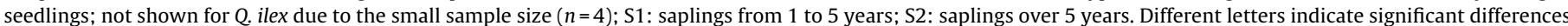

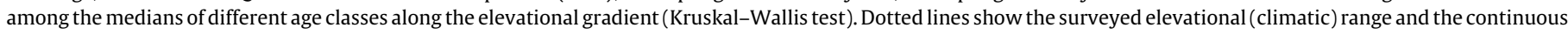

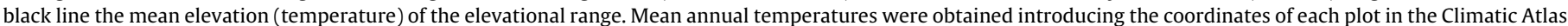
of the Iberian Peninsula (Ninyerola et al., 2005).

et al., 2013). Therefore, this outcome shows the importance that climate exerts as one of the main drivers for seedlings' survival and ingrowth rate (Urbieta et al., 2011; Vayreda et al., 2013; Carnicer et al., 2014).
Sapling abundance exhibited a common asymmetric pattern in pine saplings independently of their biogeographical origin, with more saplings in the middle-upper than in middle-lower elevations. As expected, density and basal area of conspecific 
Pinus sylvestris

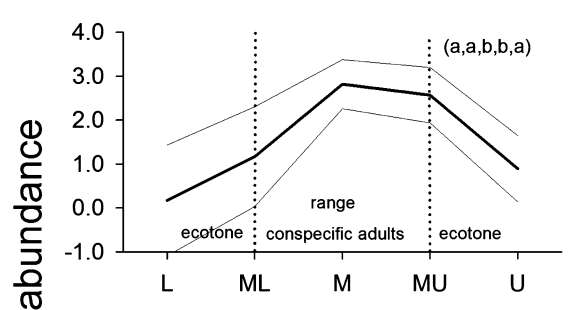

Fagus sylvatica

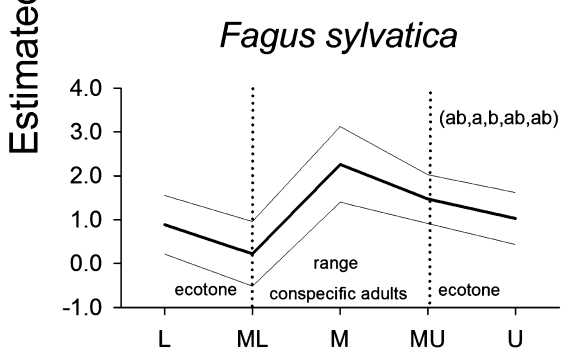

Pinus uncinata

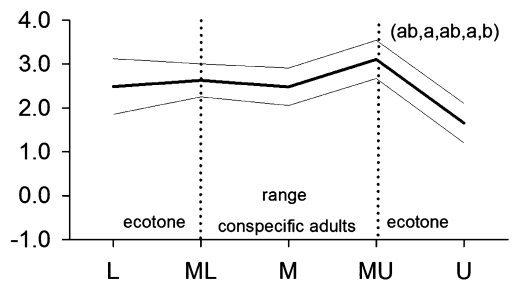

Quercus ilex

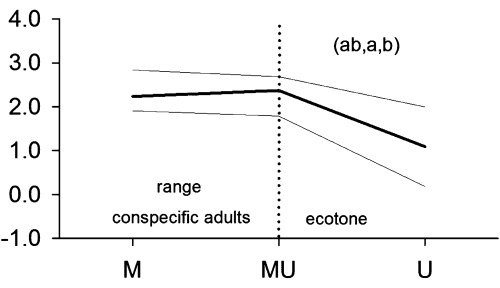

Pinus nigra
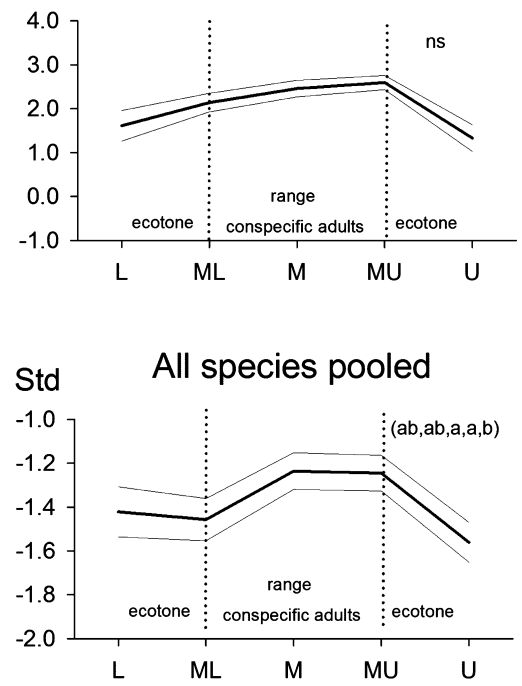

\section{Elevational transect}

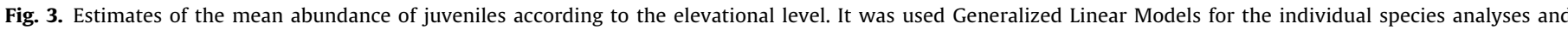

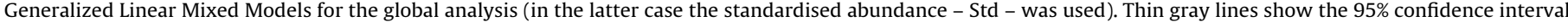

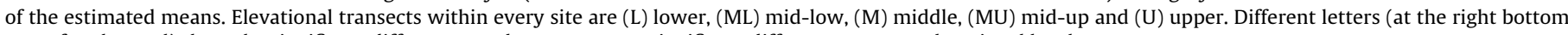
part of each panel) show the significant differences and $n s$ means non-significant differences among elevational levels.

adults were higher in the three intermediate transects than in the ecotones (Fig. 2; Fig. A.1), in agreement with the number of saplings. Within these three elevational levels, it is remarkable that, despite the higher abundance of recently emerged seedlings near or even below the middle range transects, sapling abundance was skewed to higher elevations (lower temperatures). Lacking historical records, we cannot completely dismiss that this ontogenetic shift simply renders different requirements for emergence vs. seedling survival (Werner and Gilliam, 1984), regardless of the ongoing climate changes. However, we assumed that this pattern suggests that seedling survival is greater at higher elevations where heat- and drought-stresses are typically lower compared to seedling emergence, supporting the current expectations in response to climate warming (IPCC, 2007; Hughes, 2000). Nevertheless, we recorded the lowest densities at the uppermost transects suggesting that recruitment up there may be hampered likely, either by climatic variables (not exclusively temperature and precipitation, but also radiation, freezing events, wind, etc.) and
Pinus sylvestris

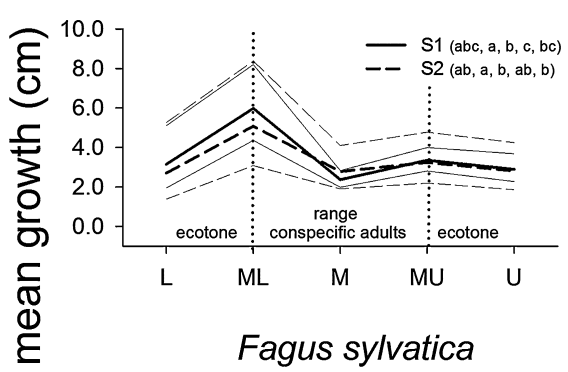

Fagus sylvatica

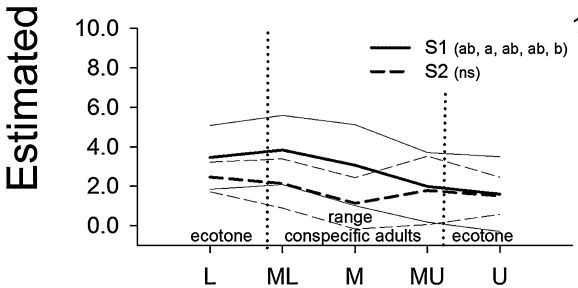

Pinus uncinata

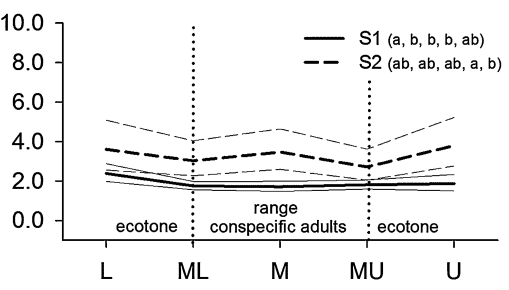

Quercus ilex

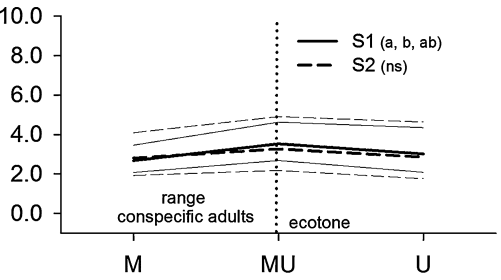

Pinus nigra
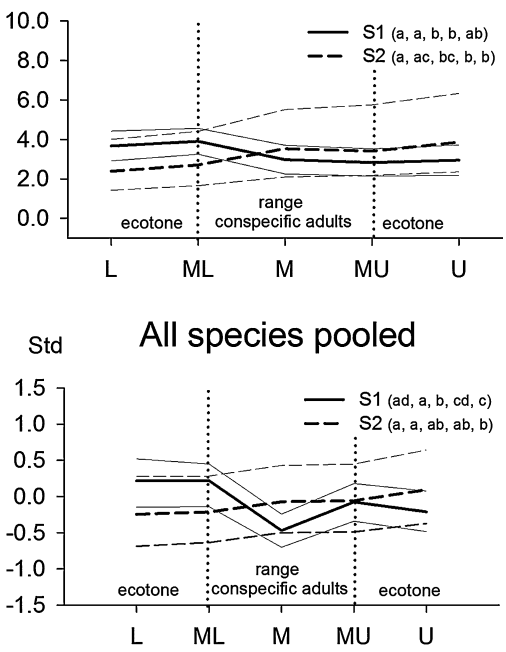

\section{Elevational transect}

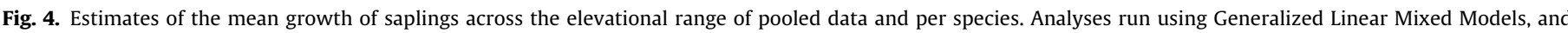

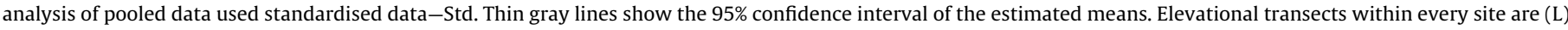

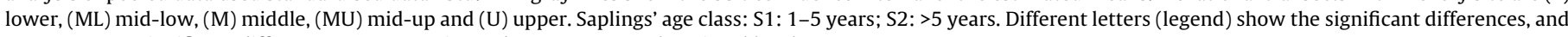
$n s$ means non-significant differences, among estimated means among elevational levels. 
Table 2

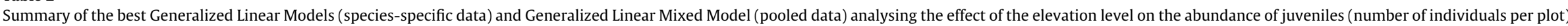

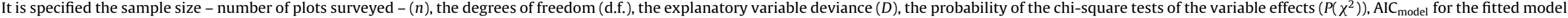

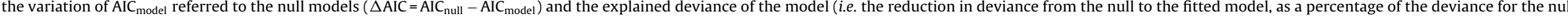

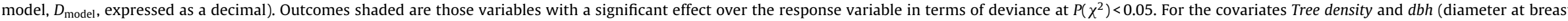
height) the sign of the effect is specified in brackets after the $P\left(\chi^{2}\right)$, when significant.

\begin{tabular}{|c|c|c|c|c|c|c|c|c|c|c|c|c|c|c|c|c|c|c|}
\hline & \multicolumn{3}{|c|}{ Pinus sylvestris $(\mathrm{n}=90)$} & \multicolumn{3}{|c|}{ Pinus uncinata $(\mathrm{n}=60)$} & \multicolumn{3}{|c|}{ Pinus nigra $(\mathrm{n}=60)$} & \multicolumn{3}{|c|}{ Fagus sylvatica $(\mathrm{n}=60)$} & \multicolumn{3}{|c|}{ Quercus ilex $(n=36)$} & \multicolumn{3}{|c|}{ All species pooled $(n=306)$} \\
\hline & $\overline{\text { d.f. }}$ & $\mathrm{D}$ & $P\left(\chi^{2}\right)$ & d.f. & $\mathrm{D}$ & $P\left(\chi^{2}\right)$ & d.f. & $\mathrm{D}$ & $P\left(\chi^{2}\right)$ & d.f. & $\mathrm{D}$ & $P\left(\chi^{2}\right)$ & d.f. & $\mathrm{D}$ & $P\left(\chi^{2}\right)$ & d.f. & $\mathrm{D}$ & $P\left(\chi^{2}\right)$ \\
\hline Site & 2 & 40.238 & $<0.0001$ & 1 & 10.439 & 0.0012 & 1 & 23.430 & 0.0000 & & & & 1 & 2.0446 & 0.0248 & - & - & - \\
\hline Elevation & 4 & 28.217 & $<0.0001$ & 4 & 21.221 & 0.0003 & 4 & 4.567 & 0.3347 & 4 & 10.001 & 0.0404 & 2 & 3.3223 & 0.0411 & 4 & 20.990 & 0.0003 \\
\hline Tree density & 1 & 3.280 & $0.0701(-)$ & & & & 1 & 4.932 & $0.0264(-)$ & & & & & & & & & \\
\hline$d b h$ & & & & & & & & & & 1 & 8.377 & $0.0038(+)$ & 1 & 4.0933 & $0.0430(+)$ & 1 & 3.840 & $0.0498(+)$ \\
\hline $\mathrm{AIC}_{\text {model }}$ & 321.00 & & & 296.21 & & & 289.39 & & & 88.46 & & & 180.60 & & & 365.02 & & \\
\hline$\triangle \mathrm{AIC}$ & 29.61 & & & 14.24 & & & 12.85 & & & 4.74 & & & 0.14 & & & 14.83 & & \\
\hline$D_{\text {model }}$ & 0.64 & & & 0.43 & & & 0.43 & & & 0.53 & & & 0.26 & & & 0.07 & & \\
\hline
\end{tabular}

Table 3

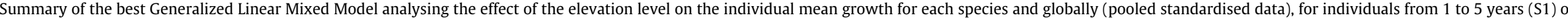

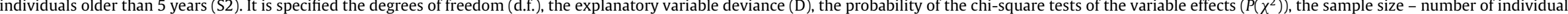

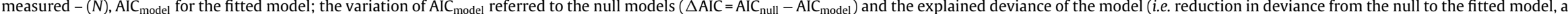

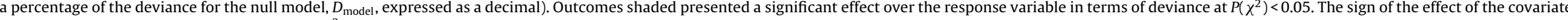
$B A$ (basal area) appears in brackets after the $P\left(\chi^{2}\right)$, when significant.

\begin{tabular}{|c|c|c|c|c|c|c|c|c|c|c|c|c|c|c|c|c|c|c|c|}
\hline & & \multicolumn{3}{|c|}{ Pinus sylvestris } & \multicolumn{3}{|c|}{ Pinus uncinata } & \multicolumn{3}{|c|}{ Pinus nigra } & \multicolumn{3}{|c|}{ Fagus sylvatica } & \multicolumn{3}{|c|}{ Quercus ilex } & \multicolumn{3}{|c|}{ All species pooled } \\
\hline & & d.f. & $D$ & $P\left(\chi^{2}\right)$ & d.f. & $D$ & $P\left(\chi^{2}\right)$ & d.f. & $D$ & $P\left(\chi^{2}\right)$ & d.f. & $D$ & $P\left(\chi^{2}\right)$ & d.f. & $D$ & $P\left(\chi^{2}\right)$ & d.f. & $D$ & $P\left(\chi^{2}\right)$ \\
\hline \multirow[t]{6}{*}{ S1 } & Elevation & 4 & 113.518 & $<0.0001$ & 4 & 11.877 & 0.0183 & 4 & 14.401 & 0.0061 & 4 & 6.726 & 0.1511 & 4 & 6.203 & 0.0450 & 4 & 112.455 & $<0.0001$ \\
\hline & $\mathrm{BA}$ & 1 & 12.304 & $0.0005(-)$ & & & & & & & 1 & 1.545 & 0.2139 & & & & 1 & 5.389 & $0.0203(-)$ \\
\hline & $N$ & 838 & & & 252 & & & 195 & & & 64 & & & 109 & & & 1458 & & \\
\hline & $\mathrm{AIC}_{\text {model }}$ & 1014 & & & 205. & & & 522.2 & & & 224. & & & 156. & & & -169.2678 & & \\
\hline & $\triangle \mathrm{AIC}$ & 115.8 & & & 3.88 & & & 14.71 & & & -1.7 & & & 2.20 & & & 107.84 & & \\
\hline & $D_{\text {model }}$ & 0.11 & & & 0.06 & & & 0.06 & & & 0.04 & & & 0.04 & & & 1.7 & & \\
\hline \multirow[t]{6}{*}{ S2 } & Elevation & 4 & 17.425 & 0.0016 & 4 & 17.695 & 0.0014 & 4 & 11.532 & $<0.0001$ & 4 & 6.238 & 0.1821 & 4 & 0.713 & 0.7001 & 4 & 9.758 & 0.0447 \\
\hline & BA & 1 & 8.586 & $0.0034(-)$ & 1 & 8.825 & $0.0030(-)$ & & & & 1 & 0.808 & 0.3687 & 1 & 3.264 & $0.0708(-)$ & 1 & 18.137 & $<0.0001(-)$ \\
\hline & $N$ & 211 & & & 332 & & & 292 & & & 26 & & & 124 & & & 985 & & \\
\hline & $\mathrm{AIC}_{\text {model }}$ & 258.7 & & & 594. & & & 295.2 & & & 73.4 & & & 162. & & & 303.9562 & & \\
\hline & $\triangle \mathrm{AIC}$ & 16.01 & & & 16.5 & & & 17.37 & & & -2.9 & & & -2.0 & & & 17.90 & & \\
\hline & $D_{\text {model }}$ & 0.1 & & & 0.04 & & & 0.08 & & & 0.11 & & & 0.03 & & & 0.09 & & \\
\hline
\end{tabular}


other local conditions. Consequently we cannot prove an expansion of the current range limits of the study species beyond their current boundary (upward migration) as other studies did (Peñuelas and Boada, 2003; Peñuelas et al., 2007; Batllori and Gutiérrez, 2008; Jump et al., 2012; Matías and Jump, 2014). In other words, our results agree with an upslope movement of central tendencies of the study species distributions but we had no evidence for an extension of the species ranges upslope (Breshears et al., 2008; Kelly and Goulden, 2008; Lenoir et al., 2008, 2009). Such a statement would have required an additional study focused at the ecotones comparing the sapling abundance of the target species with those from competing species.

The results from both Fagaceae species were a bit less clear. The elevation range of $Q$. ilex sampled in this study only covered the upper edge of its distribution, exhibiting again a decrease of the overall sapling abundance in the upper transect. However, looking at the elevational distribution of young saplings (under five years), they were more abundant near the upper ecotone compared to the older saplings, similar to the distribution of pines. This outcome agrees with studies carried out in Spain using data from the National Forest Inventories, showing an upwards shift of Q. ilex recruits towards cooler areas, especially relevant in stands where this species adjoins pine forests upslope, a situation that seems to facilitate oak seedlings success (Urbieta et al., 2011; Vayreda et al., 2013; Carnicer et al., 2014). On the other hand, F. sylvatica showed an unexpected high density of juveniles at the lower ecotone in our study. This pattern did not match with previous studies conducted in north-eastern Spain, which evidenced an upslope shift of this species during the last century with a consequent species replacement downslope (Peñuelas and Boada, 2003; Peñuelas et al., 2007). We posit that other reasons not linked with the species response to climate change may underlie this unexpected trend. In fact, the difference in the stand structure among transects may be interfering with the likely effect of the global warming over the recruitment pattern in the short term. Indeed, the lower transects of these forests showed low densities of bigger adult trees (Fig. A.1), which means stands with less multistemmed individuals. This result matches with the positive effect that $d b h$ exerted over the abundance of saplings, likely related to the higher vigour on seed production of one-stemmed individuals from the lower levels compared to the multi-stemmed individuals resulting from old coppicing (Rodríguez-Calcerrada et al., 2011).

Moreover, our study reveals opposite trends between recruitment abundance and performance across the elevational range suggesting a potential stabilising process at the population level. Unlike the sapling abundance pattern, mean growth of young saplings (S1) of every target species decreased with increasing elevation. This cohort is known to be more susceptible, not only to the climate and especially to extreme climatic events (Collins and Carson, 2004; Castro et al., 2005), but also to the effect of mammalian herbivores, which can impede regeneration in Mediterranean mountains (Zamora et al., 2001; Herrero et al., 2012). The pattern we found revealed more favourable conditions in warmer places for early recruitment performance, showing the positive role that warm temperatures may exert over growth even in relatively dry Mediterranean areas, when appropriately distributed along the year regarding the annual rainfall distribution, (see Herrero et al., 2013 for secondary growth in adult trees). Similar findings were reported by Doak and Morris (2010) studying the performance of two tundra species along their latitudinal range. They found higher growth rates at the southern edge, despite a lower survival rate of juveniles, suggesting as well a demographic compensatory effect in response to the climate shifts with latitude. Several studies have already reported evidence on the positive correlation between sapling size and their survival, including studies carried out in Mediterranean environments (Cuesta et al., 2010; García-Camacho et al., 2012; Villar-Salvador et al., 2012). Therefore, these higher individual growths of young saplings (more vulnerable) provide more chances to survive because they can overcome quicker this critical stage in terms of climate sensitivity (Pfister, 1998; Doak and Morris, 2010) and damage from browsers (Zamora et al., 2001), counterbalancing at the population level the negative effect of global warming over early survival at the trailing edges.

Nevertheless, this pattern (higher growths downslope) disappeared as saplings grew, showing again an ontogenetic shift between both cohorts (Werner and Gilliam, 1984), rendering into an idiosyncratic response of juveniles over five years among species and transects. Indeed, several studies have already proved that the niche may change over life cycle due to the different requirements and tolerance to environmental conditions (Miriti, 2006; Quero et al., 2008; Bertrand et al., 2011a). This outcome firstly warns about drawing general conclusions about the impact of global warming on plant populations without considering each particular life stage (Grubb, 1977). Moreover, the results hint that once the early seedlings are recruited, the climatic impact on the demography may be somehow attenuated by other factors that become more relevant at a local scale, like the basal area that is considered a proxy for available light. Accordingly, previous studies have supported the non-random effect that local environmental conditions (biotic and abiotic factors) exert over the juveniles' growth, including light availability (Gómez-Aparicio et al., 2008; Matías et al., 2011; Benavides et al., 2013) and plant-plant interactions (Davis et al., 1999; Ameztegui and Coll, 2013; Benavides et al., 2013). In other words, fine scale factors acting hierarchically may exacerbate (for instance, at southern, dry exposures) or mitigate (for instance, by facilitation) the impacts of the changing climate (Lloret et al., 2012).

We conclude that our results across entire elevation ranges of different species suggest the existence of a demographic compensation during the early recruitment stage in relation to the global warming impacts. Although in lower (warmer) areas fewer seedlings of different species overcome the first summer drought (i.e. main filter in Mediterranean areas), those that survive grow more than those at higher altitudes and would likely move out faster from this highly vulnerable life stage. So, we might expect that the net result turns out in certain stability at the population level, as long as climate change does not exceed certain thresholds. Thus, challenging opportunities arise to explore the persistence and relative importance of these stabilising processes along larger temporal scales, which would allow us to infer how these patterns will evolve as juveniles become adults (i.e. paying special attention on the temporal variation of ontogenetic niches shifts), and the role that local factors and management can play on population dynamics under climate change.

\section{Acknowledgments}

The authors thank all the people that made this intensive fieldwork possible, especially to R. Freire, D. López, J. Martínez, A. Rincón, G. Caballé, E. Alquézar, L. Ivorra, S. Martín, C. Rollinson and M. Kaye. We are also very grateful to J. Lenoir and another anonymous referee, whose valuable comments and suggestions have greatly improved the original manuscript. RB was funded by a Marie Curie IEF fellowship (FP7-PEOPLE-2011-IEF). Funding also was provided by the Spanish Ministry for Innovation and Science with the grant Consolider-Montes (CSD2008_00040), VULGLO (CGL2010 22180 C03 03), MOUNTAINS (CGL-2012-38427), the Community of Madrid grant REMEDINAL 2 (CM S2009 AMB 1783) and the European Union with the projects BACCARA (CE: FP7-226299, 7FP) and FunDivEUROPE (CE: FP7-ENV-2010. 265171). 


\section{Appendix A. Supplementary data}

Supplementary data associated with this article can be found, in the online version, at http://dx.doi.org/10.1016/j.ppees.2015.06. 004

\section{References}

Aitken, S.N., Yeaman, S., Holliday, J.A., Wang, T., Curtis-McLane, S., 2008. Adaptation, migration or extirpation: climate change outcomes for tree populations. Evol. Appl. 1, 95-111.

Ameztegui, A., Brotons, L., Coll, L., 2010. Land-use changes as major drivers of Mountain pine (Pinus uncinata Ram.) expansion in the Pyrenees. Global Ecol. Biogeogr. 19, 632-641.

Ameztegui, A., Coll, L., 2013. Unraveling the role of light and biotic interactions on seedling performance of four Pyrenean species along environmental gradients. For. Ecol. Manage. 303, 25-34.

Araújo, M.B., Luoto, M., 2007. The importance of biotic interactions for modelling species distributions under climate change. Global Ecol. Biogeogr. 16, 743-753.

Baldi, P., Muthuchelian, K., La Porta, N., 2012. Leaf plasticity to light intensity in Italian cypress (Cupressus sempervirens L.): adaptability of a Mediterranean conifer cultivated in the Alps. J. Photochem. Photobiol. 117, 61-69.

Batllori, E., Gutiérrez, E., 2008. Regional tree line dynamics in response to global change in the Pyrenees. J. Ecol. 96, 1275-1288.

Beckage, B., Osborne, B., Gavin, D.G., Pucko, C., Siccama, T., Perkins, T., 2008. A rapid upward shift of a forest ecotone during 40 years of warming in the Green Mountains of Vermont. Proc. Natl. Acad. Sci. U.S.A. 105, 4197-4202.

Benavides, R., Rabasa, S.G., Granda, E., Escudero, A., Hódar, J.A., Martínez-Vilalta, J., Rincón, A., Zamora, R., Valladares, F., 2013. Direct and indirect effects of climate on demography and early growth of Pinus sylvestris at the rear edge: changing roles of biotic and abiotic factors. PLoS ONE 8 (3), e59824, http://dx. doi.org/10.1371/journal.pone.0059824

Bertrand, R., Gégout, J.C., Bontemps, J.D., 2011a. Niches of temperate tree species converge towards nutrient-richer conditions over ontogeny. Oikos 120, $1479-1488$.

Bertrand, R., Lenoir, J., Piedallu, C., Riofrío-Dillon, G., de Ruffray, P., Vidal, C., Pierrat, J.C., Gégout, J.C., 2011b. Changes in plant community composition lag behind climate warming in lowland forests. Nature 479, 517-520.

Bolker, B.M., Brooks, M.E., Clark, C.J., Geange, S.W., Poulsen, J.R., Stevens, M.H.H., White, J.S.S., 2008. Generalized linear mixed models: a practical guide for ecology and evolution. Trends Ecol. Evol. 24, 127-135.

Breshears, D.D., Huxman, T.E., Adams, H.D., Zou, C.B., Davison, J.E., 2008. Vegetation synchronously leans upslope as climate warms. Proc. Natl. Acad. Sci. U.S.A. 105, $11591-11592$.

Breslow, N.E., Clayton, D.G., 1993. Approximate inference in generalized linear mixed models. J. Am. Stat. Assoc. 88, 9-25.

Carnicer, J., Coll, M., Ninyerola, M., Pons, X., Sánchez, G., Peñuelas, J., 2011. Widespread crown condition decline, food web disruption, and amplified tree mortality with increased climate change type drought. Proc. Natl. Acad. Sci. U.S.A. 108, 1474-1478.

Carnicer, J., Coll, M., Pons, X., Ninyerola, M., Vayreda, J., Peñuelas, J., 2014. Large-scale recruitment limitation in Mediterranean pines, the role of Quercus ilex and forest successional advance as key regional drivers. Global Ecol. Biogeogr. 23, 371-384.

Castro, J., Zamora, R., Hódar, J.A., Gómez, J.M., 2004. Seedling establishment of a boreal tree species (Pinus sylvestris) at its southernmost distribution limit: consequences of being in a marginal Mediterranean habitat. J. Ecol. 92, 266-277.

Castro, J., Zamora, R., Hódar, J.A., Gómez, J.M., 2005. Alleviation of summer drough boosts establishment success of Pinus sylvestris in a Mediterranean mountain: an experimental approach. Plant Ecol. 181, 191-202.

Collins, R.J., Carson, W.P., 2004. The effects of environment and life stage on Quercus abundance in the eastern deciduous forest, USA: are sapling densities most responsive to environmental gradients? For. Ecol. Manage. 201, 241-258.

Comte, L., Grenouillet, G., 2013. Do stream fish track climate change? Assessing distribution shifts in recent decades. Ecography 36, 1236-1246.

Crawley, M.J., 2002. Statistical Computing: An Introduction to Data Analysis Using S-PLUS. John Wiley \& Sons, New York.

Crimmins, S.M., Dobrowski, S.Z., Greenberg, J.A., Abatzoglou, J.T., Mynsberge, A.R., 2011. Changes in climatic water balance drive downhill shifts in plant species' optimum elevations. Science 331, 324-327.

Cuesta, B., Villar-Salvador, P., Puértolas, J., Jacobs, D.F., Rey Benayas, J.M., 2010 Why do large, nitrogen rich seedlings better resist stressful transplanting conditions? A physiological analysis in two functionally contrasting Mediterranean forest species. For. Ecol. Manage. 260, 71-78.

Davis, M.A., Wrage, K.J., Reich, P.B., Tjoelker, M.G., Schaeffer, T., Muermann, C., 1999. Survival, growth, and photosynthesis of tree seedlings competing with herbaceous vegetation along a water-light-nitrogen gradient. Plant Ecol. 145, 341-350.

Doak, D.F., Morris, W.F., 2010. Demographic compensation and tipping points in climate-induced range shifts. Nature 467, 959-962.

Dobrowski, S.Z., 2011. A climatic basis for microrefugia: the influence of terrain on climate. Global Change Biol. 17, 1022-1035.
Espelta, J.M., Riba, M., Retana, J., 1995. Patterns of seedling recruitment in West Mediterranean coppiced holm oak (Quercus ilex) forests as influenced by canopy development. J. Veg. Sci. 6, 465-472.

Games, P.A., Howell, J.F., 1976. Pairwise multiple comparison procedures with unequal N's and/or variances: a Monte Carlo Study. J. Educ. Stat. 1, 113-125.

García-Camacho, R., Albert, M.J., Escudero, A., 2012. Small-scale demographic compensation in a high-mountain endemic: the low edge stands still. Plant Ecol. Divers. 5, 37-44.

Giménez-Benavides, L., Escudero, A., Iriondo, J.M., 2007. Local adaptation enhances seedling recruitment along an altitudinal gradient in a high mountain Mediterranean plant. Ann. Bot. 99, 723-734.

Giménez-Benavides, L., Albert, M.J., Iriondo, J.M., Escudero, A., 2011. Demographic processes of upward range contraction in a long-lived Mediterranean high mountain plant. Ecography 34, 85-93.

Gimeno, T.E., Camarero, J.J., Granda, E., Pías, B., Valladares, F., 2012. Enhanced growth of Juniperus thurifera under a warmer climate is explained by a positive carbon gain under cold and drought. Tree Physiol. 32, 326-336.

Gómez-Aparicio, L., 2008. Spatial patterns of recruitment in Mediterranean plant species: linking the fate of seeds, seedlings and saplings in heterogeneous landscapes at different scales. J. Ecol. 96, 1128-1140.

Gómez-Aparicio, L., Pérez-Ramos, I.M., Mendoza, I., Matías, L., Quero, J.L., Castro, J., Zamora, R., Marañón, T., 2008. Oak seedling survival and growth along resource gradients in Mediterranean forests: implications for regeneration in current and future environmental scenarios. Oikos 117, 1683-1699.

Grubb, P.J., 1977. The maintenance of species-richness in plant communities: the importance of the regeneration niche. Biol. Rev. Cambridge Philos. Soc. 52, 107-145.

Gunderson, C.A., OíHara, K.H., Campio, C.M., Walker, A.V., Edwards, N.T., 2010. Thermal plasticity of photosynthesis: the role of acclimation in forest responses to warming climate. Global Change Biol. 16, 2272-2286.

Herrero, A., Zamora, R., Castro, J., Hódar, J.A., 2012. Limits of pine forest distribution at the treeline: herbivory matters. Plant Ecol. 213, 459-461.

Herrero, A., Rigling, A., Zamora, R., 2013. Varying climate sensitivity at the dry distribution edge of Pinus sylvestris and P. nigra. For. Ecol. Manage. 308, 50-61.

Hoef, J.M.V., Boveng, P.L., 2007. Quasi-Poisson vs. negative binomial regression: how should we model overdispersed count data? Ecology 88, 2766-2772.

Hughes, L., 2000. Biological consequences of global warming: is the signal already apparent? Trends Ecol. Evol. 15, 56-61.

IPCC, 2007. Climate change 2007: the scientific basis. In: Solomon, S., Qin, D., Manning, M., Chen, Z., Marquis, M., Averyt, K.B., Tignor, M., Miller, H.L. (Eds.), Contributions of Working Group I to the Fourth Assessment Report of the Intergovernmental Panel on Climate Change: "The Physical Science Basis". Cambridge University Press, United Kingdom and New York, pp. 1-18.

Jordano, P., Herrera, C.M., 1995. Shuffling the offspring-uncoupling and spatial discordance of multiple stages in vertebrate seed dispersal. Ecoscience 2, 230-237.

Jump, L.S., Huang, T.J., Chou, C.H., 2012. Rapid altitudinal migration of mountain plants in Taiwan and its implications for high altitude biodiversity. Ecography 35, 204-210.

Kelly, A., Goulden, M., 2008. Rapid shifts in plant distribution with recent climate change. Proc. Natl. Acad. Sci. U.S.A. 105, 11823-11826.

Le Conte, Y., Navajas, M., 2008. Climate change: impact on honey bee populations and diseases. Rev. Sci. Tech. 27, 499-510.

Lehikoinen, A., Jaatinen, K., Vähätalo, A.V., Clausen, P., Crowe, O., Deceuninckk, B., Hearn, R., Holt, C.A., Hornman, M., Keller, V., Nilsson, L., Langendoenkk, T., Tománková, I., Wahl, J., Fox, A.D., 2013. Rapid climate driven shifts in wintering distributions of three common waterbird species. Global Change Biol. 19, 2071-2081.

Lenoir, J., Gégout, J.C., Marquet, P.A., de Ruffray, P., Brisse, H., 2008. A significant upward shift of plant species optimum elevation during the 20th century. Science 320, 1768-1771.

Lenoir, J., Gégout, J.C., Pierrat, J.C., Bontemps, J.D., Dhote, J.F., 2009. Differences between tree species seedling and adult altitudinal distribution in mountain forests during the recent warm period (1986-2006). Ecography 32 $765-777$.

Lenoir, J., Gégout, J.C., Guisan, A., Vittoz, P., Wohlgemuth, T., Zimmermann, N.E., Dullinger, S., Pauli, H., Willner, W., Svenning, J.C., 2010. Going against the flow: potential mechanisms for unexpected downslope range shifts in a warming climate. Ecography 33, 295-303.

Lenoir, J., Svenning, J.C., 2015. Climate-related range shifts-a global multidimensional synthesis and new research directions. Ecography 38, 15-28.

Linares, J.C., Tíscar, P.A., 2010. Climate change impacts and vulnerability of the southern populations of Pinus nigra subsp. salzmannii. Tree Physiol. 30, $795-806$.

Lloret, F., Escudero, A., Iriondo, J.M., Martínez-Vilalta, J., Valladares, F., 2012. Extreme climatic events and vegetation: the role of stabilizing processes. Global Change Biol. 18, 797-805.

Matías, L., Gómez-Aparicio, L., Zamora, R., Castro, J., 2011. Effects of resource availability on plant recruitment at the community level in a Mediterranean mountain ecosystem. Perspect. Plant Ecol. Evol. Syst. 13, 277-285.

Matías, L., Jump, A., 2014. Asymmetric changes of growth and reproductive investment herald altitudinal and latitudinal range shifts of two woody species. Global Change Biol., http://dx.doi.org/10.1111/gcb.12683

McCullagh, P., Nelder, J., 1989. Generalized Linear Models. Chapman and Hall, London. 
McDowell, N.G., Adams, H.D., Bailey, J.D., Hess, M., Kolb, T.E., 2006. Homeostatic maintenance of Ponderosa pine gas exchange in response to stand density changes. Ecol. Appl. 16, 1164-1182.

McLaughlin, B., Zavaleta, E., 2012. Predicting responses to climate change: demography and climate microrefugia in California valley oak (Quercus lobata). Global Change Biol. 18, 2301-2312.

Miriti, M.N., 2006. Ontogenetic shift from facilitation to competition in a desert shrub. J. Ecol. 94, 973-979.

Mutke, S., Gordo, J., Climent, J., Gil, L., 2003. Shoot growth and phenology modeling of grafted stone pine (Pinus pinea L.) in Inner Spain. Ann. Forest Sci. 60, 527-537.

Nicotra, A.B., Atkin, O.K., Bonser, S.P., Davidson, A.M., Finnegan, E.J., Mathesius, U., Poot, P., Purugganan, M.D., Richards, C.L., Valladares, F., van Kleunen, M., 2010. Plant phenotypic plasticity and climate change. Trends Plant Sci. 15, 684-692.

Ninyerola, M., Pons, X., Roure, J.M., 2005. Atlas Climático Digital de la Península Ibérica. Metodología y aplicaciones en bioclimatología y geobotánica. Bellaterra: Universidad Autónoma de Barcelona, Barcelona.

Parmesan, C., Yohe, G., 2003. A globally coherent fingerprint of climate change impacts across natural systems. Nature 421, 37-42.

Pearson, R.G., Dawson, T.P., 2003. Predicting the impacts of climate change on the distribution of species: are bioclimate envelope models useful? Global Ecol. Biogeogr. 12, 361-371.

Peñuelas, J., Boada, M., 2003. A global change-induced biome shift in the Montseny mountains (NE Spain). Global Change Biol. 9, 131-140.

Peñuelas, J., Gordon, C., Llorens, L., Nielsen, T., Tietema, A., Beier, C., Bruna, P. Emmett, B., Estiarte, M., Gorissen, A., 2004. Nonintrusive field experiments show different plant responses to warming and drought among sites, seasons, and species in a north-south European gradient. Ecosystems 7, 598-612.

Peñuelas, J., Ogaya, R., Boada, M., Jump, A.S., 2007. Migration, invasion and decline: changes in recruitment and forest structure in a warming-linked shift of European beech forest in Catalonia (NE Spain). Ecography 30, 829-837.

Pfister, C., 1998. Patterns of variance in stage-structured populations: evolutionary predictions and ecological implications. Proc. Natl. Acad. Sci. U.S.A. 95, 213-218.

Pinheiro, J., Bates, D., DebRoy, S., Sarkar, D., 2014. R Core Team. nlme: linear and nonlinear mixed effects models. In: R Package Version 3.1-118.

Quero, J.L., Gómez-Aparicio, L., Zamora, R., Maestre, F.T., 2008. Shifts in the regeneration niche of an endangered tree (Acer opalus ssp. granatense) during ontogeny: using an ecological concept for application. Basic Appl. Ecol. 9, 635-644.

R Core Team, 2013. R: A Language and Environment for Statistical Computing. R Foundation for Statistical Computing, Vienna, Austria, 〈http://www.R-project.org/〉.

Rabasa, S.G., Granda, E., Benavides, R., Kunstler, G., Espelta, J.M., Ogaya, R., Peñuelas, J., Scherer-Lorenzen, M., Gil, W., Grodzki, W., Ambrozy, S., Bergh, J., Hódar, J.A., Zamora, R., Valladares, F., 2013. Disparity in elevational shifts of European trees in response to recent climate warming. Global Change Biol. 19, 2490-2499.
Richter, S., Kipfer, T., Wohlgemuth, T., Calderón Guerrero, C., Ghazoul, J., Moser, B., 2012. Phenotypic plasticity facilitates resistance to climate change in a highly variable environment. Oecologia 169, 269-279.

Rodríguez-Calcerrada, J., Pérez-Ramos, I.M., Ourcival, J.M., Limousin, J.M., Joffre, R. Rambal, S., 2011. Is selective thinning an adequate practice for adapting Quercus ilex coppices to climate change? Ann. Forest Sci. 68, $575-585$.

Ruíz-Benito, P., Gómez-Aparicio, L., Zavala, M.A., 2012. Large-scale assessment of regeneration and diversity in Mediterranean planted pine forests along ecological gradients. Divers. Distrib. 18, 1092-1106.

Thabeet, A., Vennetier, M., Gadbin-Henry, C., Denelle, N., Roux, M., Caraglio, Y., Vila B., 2009. Response of Pinus sylvestris L. to recent climatic events in the French Mediterranean region. Trees Struct. Funct. 23, 843-853.

Thuiller, W., Lavorel, S., Araújo, M.B., Sykes, M.T., Prentice, I.C., 2005. Climate change threats to plant diversity in Europe. Proc. Natl. Acad. Sci. U.S.A. 102 8245-8250

Urbieta, I.R., García, L.V., Zavala, M.A., Marañón, T., 2011. Mediterranean pine and oak distribution in southern Spain: is there a mismatch between regeneration and adult distribution? J. Veg. Sci. 22, 18-31.

Vayreda, J., Gracia, M., Martínez-Vilalta, J., Retana, J., 2013. Patterns and drivers of regeneration of tree species in forests of peninsular Spain. J. Biogeogr. 40, $1252-1265$.

Venables, W.N., Ripley, B.D., 2002. Modern Applied Statistics with S, fourth ed. Springer, New York, NY

Villar-Salvador, P., Puértolas, J., Cuesta, B., Peñuelas, J.L., Uscola, M. Heredia-Guerrero, N., Rey Benayas, J.M., 2012. Increase in size and nitrogen concentrations enhances seedling survival in Mediterranean plantations. Insights from an ecophysiological conceptual model of plant survival. New For. 43, 755-770.

Wang, T., Zhang, Q.B., Ma, K., 2006. Treeline dynamics in relation to climatic variability in the central Tianshan Mountains, northwestern China. Global Ecol. Biogeogr. 15, 406-415.

Wardle, P., Coleman, M.C., 1992. Evidence for rising upper limits of four native New Zealand forest trees. N.Z. J. Bot. 30, 303-314.

Werner, E.E., Gilliam, F.J., 1984. The ontogenetic niche and species interactions in size structured populations. Annu. Rev. Ecol. Syst. 15, 393-425.

Willms, J., Rood, S.B., Willms, W., Tyree, M., 1998. Branch growth of riparian cottonwoods: a hydrologically sensitive dendrochronological tool. Trees Struct. Funct. 12, 215-223.

Woodall, C.W., Oswalt, C.M., Westfall, J.A., Perry, C.H., Nelson, M.D., Finley, A.O., 2009. An indicator of tree migration in forests of the eastern United States. For Ecol. Manage. 257, 1434-1444.

Zamora, R., Gómez, J.M., Hódar, J.A., Castro, J., García, D., 2001. Effect of browsing by ungulates on sapling growth of Scots pine in a Mediterranean environment: consequences for forest regeneration. For. Ecol. Manage. 144, 33-42. 